\title{
Implementation of rules based computerised bedside prescribing and administration: intervention study
}

\author{
P G Nightingale, D Adu, N T Richards, M Peters
}

Wolfson Computer

Laboratory,

Department of

Medicine,

University of

Birmingham,

Queen Elizabeth

Medical Centre,

Birmingham

B15 2TH

P G Nightingale

statistician

M Peters

director

Department of

Nephrology, Queen

Elizabeth Hospital,

University Hospital

Birmingham NHS

Trust, Birmingham

B15 2TH

D Adu

consultant physician

and nephrologist

N T Richards

clinical director, renal

and urology services

Correspondence to:

P G Nightingale

P.G.Nightingale@

bham.ac.uk

BMJ 2000;320:750-3

website

extra

A figure showing the computerised system is available on the BMJ's

website

www.bmj.com

\begin{abstract}
Ojectives: To implement and assess a rules based computerised prescribing system with the aim of improving the safety of prescriptions and the administration of drugs.

Design: Analysis of performance of computerised system plus questionnaire survey of users.

Setting: 64 bed renal unit in a teaching hospital.

Intervention: Introduction of the system into routine clinical use.

Main outcome measures: Number of attempted prescriptions cancelled by the system; proportion of warning messages overridden; users' comparisons of the system with conventional procedures.

Results: Between October 1998 and August 1999 the system cancelled $58(0.07 \%)$ out of 87789 prescriptions on the grounds of clinical safety. In addition, 427 (57\%) attempted prescriptions generating high level warnings and 1257 (8\%) generating low level warnings were not completed. In a user survey $82 \%(31 / 38)$ of doctors and nurses considered the system to be an improvement on conventional procedures.

Conclusions: The system has contributed to safety and patient care. All prescriptions are complete and legible, and transcription errors have been eliminated. The system assists clinicians when they are writing a prescription by making available information on patients. The system supports clinical decision making and has been well received by doctors, nurses, and pharmacists.
\end{abstract}

\section{Introduction}

Complications arising from drug treatment are the most common cause of adverse events in hospital patients. Such complications occur in $6.5 \%$ of patients, and in $28 \%$ of cases they are preventable. ${ }^{12}$ Errors may occur from the initial decision to prescribe to the final administration of the drug. ${ }^{34}$ Adverse drug events are most commonly caused by prescribing errors, ${ }^{2}$ and these include choice of the wrong drug, dose, route, form, and frequency or time of administration. ${ }^{4-6}$ Errors occur in up to $5 \%$ of prescriptions, ${ }^{7}$ often because the prescriber does not have immediate access to the relevant information relating to the drug (its indications, contraindications, interactions, therapeutic dose, or side effects) or the patient (allergies, other medical conditions, or latest laboratory results). ${ }^{6}$ Hand written prescription sheets can contribute to drug errors in that they may be illegible, incomplete, or subject to transcription errors when rewritten. In addition, the prescription sheets themselves may be temporarily unavailable or lost.

Electronic drug prescribing provides one method of reducing drug errors. ${ }^{89}$ An immediate benefit is improvement in the legibility of prescriptions. One study concluded that improved information systems could contribute to the prevention of $78 \%$ of errors leading to adverse drug events. ${ }^{4}$ Computerised systems containing rules to prevent incorrect or inappropriate prescribing have increased the appropriateness of drug treatment and reduced the incidence of errors. $^{10-16}$

Despite the advantages of such systems, they are not in widespread use. In primary care, the initial reaction of users to the PRODIGY (prescribing rationally with decision support in general practice study) prescribing system was that it overwhelmed them with information and prolonged consultations. ${ }^{17}$ In secondary care, a major difficulty has been making the system available where it is needed without placing a terminal at each patient's bedside. We developed a rules based system for prescribing and recording the administration of drugs which can be accessed from the patient's bedside using portable wireless terminals.

\section{Methods}

The 64 bed renal services unit within University Hospital Birmingham is a major centre for the provision of medical and surgical services for patients with renal disease. Currently the unit looks after more than 500 patients with end stage renal failure and 500 patients who have had renal transplantation; over 100 renal transplantations are performed annually.

\section{System design}

In 1996 the renal unit and Wolfson Computer Laboratory decided to develop a rules based computerised prescribing system with the aim of improving the safety of prescriptions and administration of drugs. Important considerations in the design of the system were ease and speed of use and availability to clinical staff throughout the unit. The system uses a standard Microsoft Windows graphical interface and was designed to be used with pen based portable computers.

In order to ensure the availability of information relevant to safe prescribing and administration, the system contains integrated patient specific data including demographics, main diagnoses, drug allergies and other medical conditions, current drug treatment, previous treatment, laboratory results, radiology reports, and weight. The system calculates creatinine clearance using the formula of Cockcroft and Gault. ${ }^{18}$ Basic demographic details (name, date of birth, sex, consultant, specialty, and location) are obtained from the hospital patient administration system and laboratory and radiology data from the relevant computer systems. Other information, such as a patient's allergies or medical conditions, have to be entered by hand.

\section{Drug dictionary}

The system's "drug dictionary" contains information on the commonly prescribed drugs. The drug diction- 
ary can contain the following information for each drug: allowable routes, forms, and strengths; default dose and frequency; maximum recommended single and daily doses; interactions with other drugs or drug classes; contraindications; side effects; and special instructions. The system can be set up to allow entry of drug doses as a function of the patient's weight. The data in the dictionary were obtained from relevant literature and drug data sheets as well as the experience of renal clinicians and pharmacists. Dose modifications for renal function are incorporated in the dictionary. Most of the data can be imported from a commercial drug database and can easily be regularly updated.

\section{Rules}

When a doctor prescribes a drug for a patient, rules within the system relate the information in the dictionary for the new drug to that on drugs already prescribed and to the patient specific data. This triggers the display of warning messages when appropriate. If the interaction or contraindication is minor the warnings can be acknowledged and the prescription completed. Prescribers do not have to give a reason for overriding warnings but more serious warnings require prescribers to enter their password. Some warnings are considered so serious that they cannot be overridden-for example, certain drug allergies.

Rules are also applied at the time of administration, warning nurses if they attempt to give a drug too soon after the previous dose or if a patient is prescribed more than one drug containing the same ingredient. Since the system contains both laboratory and drug data for a patient, it can highlight undesirable combinations (such as warning if a patient prescribed azathioprine has a low white cell count). Such alerts are triggered either by the result being received or by the drug being prescribed and are displayed on the system immediately.

Agreed protocols for treatment of specific conditions are included in the system. The appropriate prescriptions can be generated by selecting the relevant protocol for a patient.

\section{Altering prescribing habits}

Drugs that are strongly contraindicated in renal failure may be made unavailable to all prescribers or available only to those with a certain privilege level (such as consultants only). In addition, the system contains the concept of "alternative drugs," which can be used to direct the prescriber away from the drug they have selected to others that are preferred on the grounds of efficacy, availability, or cost. Restrictions can also be placed on the duration of prescriptions-for example, intravenous antibiotics limited to three days.

\section{Backup and security}

A second system, which is continuously updated from the live system, provides resilience in the event of a hardware failure. Details of prescriptions and administrations are also written to a document archive, which is held on a computer in the ward and can be used independently of the hospital network. If both main systems are unavailable current details of patients' drug treatment can be printed from the document archive.

Each user has a unique code and a confidential password, both of which are needed to log into the system. The privileges assigned to a user determine which actions are available to them: the user's code is associated with any actions performed while they are logged in.

\section{Use of system}

Before the system was introduced in January 1998, all clinical staff working in the renal unit were trained in its use. New doctors and nurses are trained when they arrive in the unit. The training sessions last about 90 minutes for doctors and 45 minutes for nurses.

Doctors, nurses, and pharmacists take a wireless terminal with them on their rounds so that they can access the system from the bedside. The system can be used to review drug treatment, laboratory results, and radiology reports; to prescribe and record administration of drugs and intravenous fluids; and to request laboratory investigations.

\section{Prescribing}

Doctors must admit patients on to the system, entering any known allergies and other relevant medical conditions, before prescribing any drugs for them. The doctor selects the drug to be prescribed and in most cases is presented with a default route, form, dose, frequency, duration, and round times for that drug. The doctor completes the prescription by entering the start time and is presented with any warning messages. On the basis of these warnings the doctor decides whether to continue with the prescription (in which case the warnings must be acknowledged), modify the prescription, or abandon it altogether.

Discharge drugs are prescribed by copying the relevant inpatient prescriptions and modifying these as required. The resulting prescriptions are listed on the discharge letter produced by the system. If the patient is subsequently readmitted, these prescriptions are proposed as the basis for the inpatient prescriptions for the new episode (information on allergies and other medical conditions is also carried forward from previous episodes).

Administering drugs

Nurses use the system to record the administration of drugs. The system gives a list of patients, identifies those who require drugs at each drug round, and, once a patient has been selected, lists the prescriptions

Table 1 Prescriptions disallowed by the system between October 1998 and August 1999

\begin{tabular}{lc} 
Reason disallowed & No of prescriptions \\
\hline Allergy to penicillin & 24 \\
\hline Allergy to cephalosporins & 10 \\
\hline Allopurinol-cyclophosphamide interaction & 7 \\
\hline Verapamil- $\beta$ blocker interaction & 5 \\
\hline Vancomycin-bumetanide interaction & 3 \\
\hline Verapamil-digoxin interaction & 3 \\
\hline Allergy to erythromycin & 2 \\
\hline Allopurinol-azathioprine interaction & 2 \\
\hline Allergy to azathioprine & 1 \\
\hline Diclofenac-warfarin interaction & 1 \\
\hline
\end{tabular}


Table 2 Prescription warning messages generated by computerised system from October 1998 to August 1999

\begin{tabular}{lrr} 
Category & $\begin{array}{c}\text { No of } \\
\text { warning } \\
\text { messages }\end{array}$ & $\begin{array}{r}\text { No (\%) of } \\
\text { prescriptions } \\
\text { completed }\end{array}$ \\
\hline Disallowed & 58 & 0 \\
\hline Contraindications & 37 & 0 \\
\hline Interactions & 21 & \multicolumn{1}{c}{0} \\
\hline Password level warnings & 749 & $322(43)$ \\
\hline Contraindications & 141 & $103(73)$ \\
\hline Interactions & 99 & $84(85)$ \\
\hline Maximum recommended single dose exceeded & 206 & $89(43)$ \\
\hline Maximum recommended daily dose exceeded & 303 & $46(15)$ \\
\hline Low level warnings & 16607 & $15350(92)$ \\
\hline Contraindications & 793 & $677(85)$ \\
\hline Interactions & 15743 & $14635(93)$ \\
\hline Maximum recommended single dose exceeded & 46 & $25(54)$ \\
\hline Maximum recommended daily dose exceeded & 25 & $13(52)$ \\
\hline
\end{tabular}

Table 3 Examples of attempted doses that produced warning messages

\begin{tabular}{lcc} 
Drug and form & $\begin{array}{c}\text { Attempted } \\
\text { dose }\end{array}$ & $\begin{array}{c}\text { Maximum } \\
\text { recommended } \\
\text { dose }\end{array}$ \\
\hline Single doses & $68 \mathrm{mg}$ & $16 \mathrm{mg}$ \\
\hline Doxazosin tablets & $24000 \mathrm{units}$ & $5000 \mathrm{units}$ \\
\hline Heparin injection & $50 \mathrm{mg}$ & $20 \mathrm{mg}$ \\
\hline Morphine injection & $20 \mathrm{mg}$ & $6 \mathrm{mg}$ \\
\hline Prazosin tablets & $150 \mathrm{mg}$ & $50 \mathrm{mg}$ \\
\hline Ranitidine injection & & \\
\hline Daily doses & $3 \mathrm{~g}$ & $1.2 \mathrm{~g}$ \\
\hline Amiodarone injection & $3.6 \mathrm{mg}$ & $1.5 \mathrm{mg}$ \\
\hline Atropine injection & $120 \mathrm{mg}$ & $60 \mathrm{mg}$ \\
\hline Diamorphine injection & $1 \mathrm{mg}$ & $0.5 \mathrm{mg}$ \\
\hline Digoxin tablets & $120 \mathrm{mg}$ & $40 \mathrm{mg}$ \\
\hline Metoclopramide injection & $180 \mathrm{mg}$ & $60 \mathrm{mg}$ \\
\hline Nifedipine capsules & $120 \mathrm{mg}$ & $20 \mathrm{mg}$ \\
\hline Salbutamol nebuliser solution &
\end{tabular}

they are due to be given. The nurse records each administration or the reason why the drug was not administered; non-administration is brought to the attention of the nurse conducting the next drug round. Nurses can write messages on the system for

Table 4 Doctors' and nurses' views on computerised system compared with normal prescribing and administration procedures

No $(\%)$ responding System better No difference System worse

\begin{tabular}{lccc}
\hline Doctors $(\mathrm{n}=14)$ : & & & \\
\hline Prescribing on ward rounds & $9(64)$ & $4(29)$ & $1(7)$ \\
\hline Prescribing discharge drugs & $14(100)$ & 0 & 0 \\
\hline Other prescribing & $9(69)$ & $3(23)$ & $1(8)$ \\
\hline Time taken on ward rounds & $9(64)$ & $4(29)$ & $1(7)$ \\
\hline Messages from nurses and pharmacists & $4(29)$ & $5(36)$ & $5(36)$ \\
\hline Nurses $(\mathrm{n}=24):$ & & \\
\hline Administration on drug rounds & $17(74)$ & $6(26)$ & 0 \\
\hline Other administration & $11(46)$ & $7(29)$ & $6(25)$ \\
\hline Nurse prescribing & $6(25)$ & $3(13)$ & $15(63)$ \\
\hline Time taken on drug rounds & $8(35)$ & $9(39)$ & $6(26)$ \\
\hline Messages to doctors & $10(42)$ & $8(33)$ & $6(25)$ \\
\hline Doctors and nurses $(\mathrm{n}=38):$ & & & \\
\hline Availability of data & $37(97)$ & $1(3)$ & 0 \\
\hline Legibility & $36(95)$ & $2(5)$ & 0 \\
\hline Convenience & $22(58)$ & $13(34)$ & $3(8)$ \\
\hline Safety & $26(68)$ & $8(21)$ & $4(11)$ \\
\hline Overall opinion & $31(82)$ & $7(18)$ & 0 \\
\hline
\end{tabular}

the attention of doctors. They are also responsible for printing the requests to pharmacy for supply of discharge drugs, at which time the discharge letter and a patient information sheet are printed. The information sheet contains information about the patient's discharge drugs, including the dose, side effects, and any special instructions. Once a patient has been discharged the nurse removes them from the patient list.

\section{Pharmacy review}

Pharmacists use the system to review patients' current and previous drugs. The list of patients indicates who has a new prescription that requires validation by a pharmacist. When a patient has been selected, these prescriptions are displayed and the pharmacist may then validate them or attach a message to the prescription for the attention of the doctor.

\section{User survey}

In May 1998 questionnaires were sent to all 18 doctors and 34 nurses working in the renal unit to elicit their opinions of the system. No follow up questionnaire was sent to non-responders.

\section{Results}

Since the system was introduced into clinical practice in January 1998, there have been 12.2 hours $(0.07 \%)$ of unscheduled downtime, including failures of the hospital network. A total of 1646 patients (958 men and 688 women, mean age 54.4 years) have had their drugs prescribed and administered through the system.

Between October 1998 and August 1999 there were 87789 new prescriptions. During this period 58 $(0.07 \%)$ attempted prescriptions were disallowed on clinical grounds (table 1). Table 2 shows the total number of prescription warning messages generated by the system and how many of those attempted prescriptions were completed-that is, how many warnings were overridden. Warnings relating to maximum recommended doses were least likely to be overridden. Table 3 lists some examples of attempted doses that produced warning messages. In none of these cases was the prescription completed.

Responses to the user questionnaire were received from $14(78 \%)$ doctors and $24(71 \%)$ nurses. Twelve $(86 \%)$ doctors and $21(88 \%)$ nurses found the system easy to use. Thirty one $(82 \%)$ respondents preferred the system to normal prescribing and administration procedures (table 4). Doctors perceived benefit in terms of prescribing and nurses in terms of administration; neither group felt that the time required for these activities was significantly greater than before introduction of the system.

\section{Discussion}

The rules based computerised drug prescribing and administration system was designed to guide medical and nursing decision making and does not replace it. The system has been in continuous clinical use for 21 months, during which time there have been no hand written prescriptions. This has meant that all prescriptions are complete and legible, transcription errors 


\section{What is already known on this topic}

Prescription errors often occur because the prescriber does not have immediate access to relevant information relating to the drug or the patient

Computerised systems containing rules to prevent incorrect or inappropriate prescribing increase the appropriateness of drug treatment and reduce errors

Such systems have not been widely implemented because of difficulty providing decision support at patients' bedside

\section{What this study adds}

A rules based system for prescribing and recording the administration of drugs that can be accessed from the patient's bedside through wireless terminals was introduced

Over 11 months the system stopped 58 unsafe prescriptions and gave over 700 high level warnings

The system was considered an improvement by most doctors and nurses

have been eliminated, and patients' prescriptions are always available. Prescriptions are checked against patient data as well as information on drug interactions and maximum recommended doses, which increases the likelihood that prescribing will be safe. The prescriptions abandoned as a result of warning messages constitute an important contribution to safety and patient care. We have also found that the system facilitates the introduction of treatment protocols into clinical care and makes audit of drug prescribing easy (data not shown).

Because the system has been designed to support clinical decision making rather than to control it, it has been well received by doctors, nurses, and pharmacists. It was seen as improving the effectiveness and safety of patient care. Most of the prescription warnings generated by the system are low level interaction warnings, which are usually overridden. However, the purpose of these warnings is to give information on potential interactions, which would otherwise have to be sought in a drug formulary. The warnings of drug interactions and contraindications reinforce users' knowledge of drugs.

We have not yet examined the effect of the introduction of the system on patient outcomes, but this is an important area for future study. Although the system is generic in concept and potentially applicable to any specialty, it is currently only in use in the renal unit, and its effectiveness in other settings remains to be examined.

We thank the staff of the Queen Elizabeth Hospital renal unit and pharmacy and the programming and development teams at Wolfson Computer Laboratory for their contributions to the design and implementation of the system.

Contributors: PGN designed the questionnaire, analysed all the data, and drafted the paper. DA, NTR, and MP initiated the introduction of the system and participated in the interpret- ation of the data and writing the paper. PGN will act as guarantor.

Funding: None.

Competing interests: Since its development the system has been acquired by McKesson HBOC. Wolfson Computer Laboratory has a contract with McKesson HBOC to develop the system further and both the laboratory and the renal unit receive royalties from sales of the system. NTR and MP have been reimbursed by McKesson HBOC for attending several conferences.

1 Leape LL, Brennan TA, Laird N, Lawthers AG, Localio AR, Barnes BA, et al. The nature of adverse events in hospitalized patients: results of the Harvard medical practice study II. N Engl J Med 1991:324:377-84.

2 Bates DW, Cullen DJ, Laird N, Petersen LA, Small SD, Servi D, et al. Incidence of adverse drug events and potential adverse drug events: implications for prevention. JAMA 1995;274:29-34

3 Ferner RE. Errors in prescribing and giving drugs. Journal of the Medical Defence Union 1992;8:60-3.

4 Leape LL, Bates DW, Cullen DJ, Cooper J, Demonaco HJ, Gallivan T, et al. Systems analysis of adverse drug events. JAMA 1995;274:35-43.

5 Lesar TS, Briceland LL, Delcoure K, Parmalee JC, Masta-Gornic V, Pohl $\mathrm{H}$. Medication prescribing errors in a teaching hospital. JAMA 1990;263:2329-34.

6 Lesar TS, Briceland L, Stein DS. Factors related to errors in medication prescribing. JAMA 1997;277:312-7.

7 Bates DW, Boyle DL, Vander Vliet M, Schneider J, Leape L. Relationship between medication errors and adverse drug events. J Gen Intern Med 1995; 10:199-205.

8 Wyatt J, Walton R. Computer based prescribing: improves decision making and reduces costs. BMJ 1995;311:1181-2.

9 Schiff GD, Rucker TD. Computerized prescribing: building the electronic infrastructure for better medication usage. JAMA 1998;279:1024-9.

10 Johnston ME, Langton KB, Haynes RB, Mathieu A. Effects of computer based clinical decision support systems on clinician performance and patient outcome: a critical appraisal of research. Ann Intern Med 1994;120:135-42.

11 Evans RS, Classen DC, Pestotnik SL, Lundsgaarde HP, Burke JP. Improving empiric antibiotic selection using computer decision support. Arch Intern Med 1994;154:878-84.

12 Pestotnik SL, Classen DC, Evans RS, Burke JP. Implementing antibiotic practice guidelines through computer-assisted decision-support: clinical and financial outcomes. Ann Intern Med 1996;124:884-90.

13 Evans RS, Pestotnik SL, Classen DC, Clemmer TP, Weaver LK, Orme JF, et al. A computer-assisted management program for antibiotics and other anti-infective agents. N Engl J Med 1998;338:232-8.

14 Shojania KG, Yokoe D, Platt R, Fiskio J, Ma'luf N, Bates DW. Reducing vancomycin use utilizing a computer guideline: results of a randomized controlled trial. J Am Med Inform Assoc 1998;5:554-62.

15 Bates DW, Leape LL, Cullen DJ, Laird N, Petersen LA, Teich JM, et al Effect of computerized physician order entry and a team intervention on prevention of serious medication errors. JAMA 1998;280:1311-6.

16 Raschke RA, Gollihare B, Wunderlich TA, Guidry JR, Leibowitz AI, Peirce JC, et al. A computer alert system to prevent injury from adverse drug events: development and evaluation in a community teaching hospital. JAMA 1998;280:1317-20.

17 Purves IN. PRODIGY: implementing clinical guidance using computers Br J Gen Pract 1998;48:1552-3.

18 Cockcroft DW, Gault MH. Prediction of creatinine clearance from serum creatinine. Nephron 1976;16:31-41.

(Accepted 14 February 2000)

\section{Corrections and clarifications}

Reviews

In Simon Chapman's review of the book Curbing the Epidemic: Governments and the Economics of Tobacco Control (15 January, p 192) we unfortunately misspelt the name of one of the book's editorsPrabhat Jha.

Not time to put cot death to bed

We inadvertently forgot to incorporate a couple of late changes to this article by Sylvia Limerick

(11 September, pp 698-700). In the second paragraph on $\mathrm{p}$ 699, disease categories were from ICD-9 (not ICD-10), and in the second paragraph on $\mathrm{p} 700$, the reference is 7 (not 2).

Recent advances in intensive care

In this article by Stephen Stott (5 February, pp 358-61)

the figure showing the technique of percutaneous tracheostomy (p 360) was adapted from a diagram provided by Cook Critical Care. 